\title{
Electronic transport properties of microcrystalline silicon thin films prepared by VHF-PECVD
}

\author{
S. OKUR, M. GÜNEŞ, O. GÖKTAŞ \\ Department of Physics, Izmir Institute of Technology, Gülbahçe Kampusu, Urla, Izmir, \\ TR-35430, Turkey \\ F. FINGER, R. CARIUS \\ Institut für Photovoltaik, Forschungszentrum Jülich GmbH, 52425 Jülich, Germany
}

\begin{abstract}
Steady-state photocarrier grating (SSPG) and steady-state photoconductivity, $\sigma_{\mathrm{ph}}$, experiments have been carried out to investigate the electronic transport properties of undoped hydrogenated microcrystalline silicon $(\mu \mathrm{c}-\mathrm{Si}: \mathrm{H})$ films prepared with very high frequency plasma enhanced chemical vapor deposition (VHF-PECVD). Material with different crystalline volume fractions was obtained by variation of the silane concentration (SC) in the process gas mixture. Pure amorphous silicon material was investigated for comparison. The ambipolar diffusion length, $L_{a m b}$, which is dominated by the minority carrier properties, is obtained both from the best fit to the experimental photocurrents ratio, $\beta$, versus grating period $(\Lambda)$, and from the "Balberg plot" for the generation rates between $10^{19}$ and $10^{21} \mathrm{~cm}^{-3} \mathrm{~s}^{-1}$. $L_{\mathrm{amb}}$ increases from $86 \mathrm{~nm}$ with increasing SC and peaks around $200 \mathrm{~nm}$ for the $S C=5.6 \%$ and decreases again for higher $S C s$. $L_{\text {amb }}$ values obtained from the intercept of the Balberg plot result in a small difference of around $5 \%$ for most of the samples. Minority carrier mobility-lifetime $(\mu \tau)$-products are much lower than those of majority carriers, however, both majority and minority carrier $\mu \tau$-products in microcrystalline silicon are higher than those of undoped hydrogenated amorphous silicon. The grating quality factor $\left(\gamma_{0}\right)$ changes from 0.70 to 1.0 indicating almost negligible surface roughness present in the samples.
\end{abstract}

\section{(C) 2004 Kluwer Academic Publishers}

\section{Introduction}

Hydrogenated microcrystalline silicon $(\mu \mathrm{c}-\mathrm{Si}: \mathrm{H})$ has become an important material for large area electronics such as solar cells [1-4]. The wide range of electronic properties is due to its heterogeneous microstructure, which is mainly controlled by the silane concentration (SC) in the silane-hydrogen gas mixture of the deposition process [2]. Steady-state photocarrier grating (SSPG) technique $[5,6]$ developed for a-Si: $\mathrm{H}$ films is used to study electronic transport properties of $\mu \mathrm{c}-\mathrm{Si}: \mathrm{H}$ films under illumination [1]. Ambipolar diffusion length, $L_{\mathrm{amb}}$, measured by the SSPG technique gives a direct access to $\mu \tau$ products of minority carriers, which was shown to be an essential transport parameter in p-i-n type solar cells [1]. It was also found that the highest efficiency solar cells were produced for the silane concentrations of $5 \%$, which results in a material close to the amorphous phase transition. In this study, steady-state photoconductivity, $\sigma_{\mathrm{ph}}$, and the SSPG techniques were used to investigate both the majority and the minority carrier transport properties of $\mu \mathrm{c}-\mathrm{Si}: \mathrm{H}$ films [1] with different structural composition ranging from highly crystalline to mixed phase of crystalline and amorphous prepared using different silane concentrations.

\section{Experimental methods}

Undoped $\mu \mathrm{c}-\mathrm{Si}$ : $\mathrm{H}$ films with thickness between $400 \mathrm{~nm}$ and $800 \mathrm{~nm}$ were prepared using a multi-chamber deposition system consisting of six parallel plate reactors at $95 \mathrm{MHz}$ plasma excitation frequency and varying silane concentrations (gas flow ratio, $\mathrm{SC}=\left[\mathrm{SiH}_{4}\right] /$ $\left[\mathrm{SiH}_{4}+\mathrm{H}_{2}\right]$ ) between $3 \%$ and $6.3 \%$ [2]. The applied discharge power was $8 \mathrm{~W}$ on a substrate area of $10 \times 10 \mathrm{~cm}^{2}$ and the process gas total pressure was 300 mTorr. The system is optimized to process at temperature of $200^{\circ} \mathrm{C}$. The films were deposited on glass substrates (Corning 7059 and/or Corning 1737), partly covered with $100 \mathrm{~nm}$ electron beam evaporated chromium films to cut off contribution from the glass for the Raman measurements. The Raman scattering experiment was performed using $488 \mathrm{~nm}$ laser light. The control sample of a-Si : $\mathrm{H}$ film was prepared using a standard DCglow discharge method given elsewhere [7].

Experimental configuration for the SSPG technique is shown in Fig. 1 [5]. A He-Ne Laser with wavelength of $\lambda=633 \mathrm{~nm}$ was used and chopped at the frequency of $40 \mathrm{~Hz}$ to measure small-signal photocurrent between the coplanar electrodes $(\mathrm{gap}=0.5 \mathrm{~mm})$ of $\mu \mathrm{c}-\mathrm{Si}: \mathrm{H}$ samples using a lock-in amplifier. The polarized laser light is split into two coherent beams of intensities $I_{1}$ and $I_{2}$ by using a 


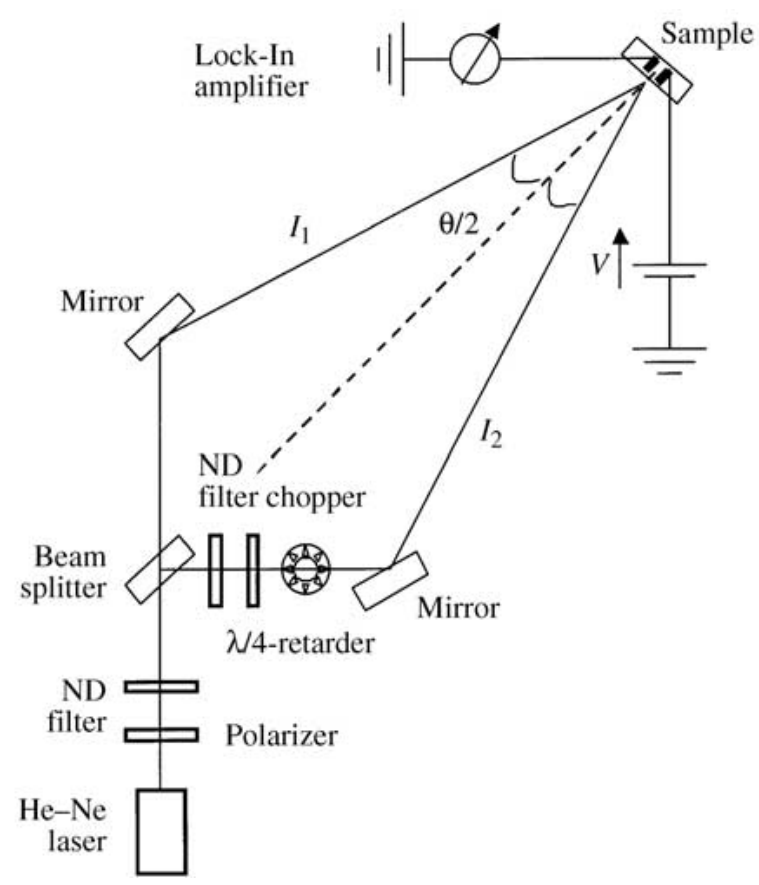

Figure 1 Experimental setup used to measure the ambipolar diffusion length in SSPG technique.

beam splitter. The intensity ratio of the beams $\left(\mathrm{I}_{2} / \mathrm{I}_{1}\right)$ is reduced to $5 \%$ using a neutral density (ND) filter. A quarter wavelength retarder is used for the case of interference and it is rotated by $90^{\circ}$ for no interference condition. The two beams are made to coincide on the sample by two mirrors with an angle symmetric around the normal to the sample surface to obtain equal beam paths. The sample is moved towards the beam splitter along the normal to change the grating period $(\Lambda)$ between $0.5 \mu \mathrm{m}$ and $3 \mu \mathrm{m}$. Then, the a.c. photocurrents $J_{\text {coh }}$, and, $J_{\text {incoh }}$ are measured for the interference and no interference conditions, respectively. Steady-state photoconductivities were measured in the Ohmic region of the coplanar contacts for generation rates between $10^{15}$ to $10^{22} \mathrm{~cm}^{-3} \mathrm{~s}^{-1}$. Interference filters $(800 \mathrm{~nm}$ and $750 \mathrm{~nm})$ were used to provide volume absorbed light for uniform photocarrier generation. Generation rate calculation for the laser light at $633 \mathrm{~nm}$ is not straightforward. Certain approximations were applied. Relative intensity versus photoconductivity curves for interference filters $800 \mathrm{~nm}$ and $750 \mathrm{~nm}$, and for the bandpass filter RG610 are found to be parallel for most of the samples, indicating the same exponent $\gamma$. Uniform generation rate is only calculated for $800 \mathrm{~nm}$ filter using calibrated flux, a constant reflection coefficient $(R)$, film thickness, $t$, and absorption coefficient $\alpha(800 \mathrm{~nm})$ obtained from the photothermal deflection spectroscopy measurement of the same sample. Since $\alpha t \ll 1$ for $800 \mathrm{~nm}$ for the samples, generation rate is calculated from the equation, $G=$ Flux $*(1-R) *(1-\exp (-\alpha t)) / t$. When energy of monochromatic filter increases such as $750 \mathrm{~nm}$ and other lower wavelengths, calculated generation rate versus photoconductivity curves do not overlap with that of $800 \mathrm{~nm}$ filter due to non-uniform absorption of light throughout the film. However, effective generation rate for $750 \mathrm{~nm}$ and RG610 can be obtained by normalizing relative intesity versus photoconductivity curve to that of $800 \mathrm{~nm}$ filter (since the exponent $\gamma$ is the same for all filters) implying that for the same photoconductivity values measured by different filters, the generation rate is assumed to be the same. It was found that for most of the samples this assumption is valid. Then, the straight line of generation rate versus photoconductivity curve is extended to higher generation rates. Higher generation rates corresponding to the photoconductivity values measured using $633 \mathrm{~nm}$ laser light are finally determined from reading on the straight line. In the SSPG experiment [6], two coherent laser beams are used to create photocarrier distribution due to interference fringes between coplanar electrodes of a sample. The ratio of the interference photocurrent during the coherent illumination, $J_{\text {coh }}$, to the photocurrent, $J_{\text {incoh }}$, of the incoherent laser beams $\left(\beta=J_{\text {coh }} / J_{\text {incoh }}\right)$ is measured for different grating periods, $\Lambda$. The relationship between $\beta$ and $\Lambda$ is given as $[5,6]$,

$$
\begin{gathered}
\beta=1-2 \phi\left(1+4 \pi^{2} L_{\mathrm{amb}}^{2} / \Lambda^{2}\right)^{-2} \\
\Lambda^{-2}=[\sqrt{\phi} \sqrt{2 /(1-\beta)}-1] /\left(2 \pi L_{a m b}\right)^{2}
\end{gathered}
$$

where $\phi$ is the grating quality parameter defined as $\phi=\gamma_{0} \gamma \gamma_{d}$, where $\gamma_{0}$ is defined to be the grating quality factor, determined using the experimental $\gamma$, the exponent of the $\sigma_{\mathrm{ph}}$ power law on generation rate $G$, the dark conductivity reducing factor defined as $\gamma_{d}=\sigma_{\mathrm{ph}} /\left(\sigma_{\mathrm{ph}}+\sigma_{\text {dark }}\right)$, and the best fit parameter $\phi$. The grating period $\Lambda$ is equal to $\lambda /[2 \sin (\theta / 2)]$, where $\lambda$, is the laser wavelength and $\theta$ is the angle between the two light beams. $L_{\mathrm{amb}}$ is obtained from a fit to Equation 1 . Another simple way of finding $L_{\mathrm{amb}}$ is to use the intercept of the so-called "the Balberg plot" [8], which is a rearrangement of Equation 1, where $\Lambda^{-2}$ is a linear function of $(2 /(1-\beta))^{1 / 2}$ as given in Equation 2. In addition, using the $L_{\mathrm{amb}}$, the quasi-Fermi level parameter $b$ can be calculated as [1],

$$
\frac{b}{(b+1)^{2}}=\frac{G q^{2} L_{\mathrm{amb}}^{2}}{k T \sigma_{\mathrm{ph}}(1+\gamma+\delta)}
$$

where $T$ is temperature and $\delta$ is the exponent in the relationship of $L_{\mathrm{amb}}^{2} \propto G^{\delta}$. The minority carrier $\mu_{p}^{o} \tau_{p}^{R}$. product can be extracted from the Equation 2 of Droz et al. [1] as,

$$
\mu_{p}^{o} \tau_{p}^{R}=\frac{\mu_{n}^{o} \tau_{n}^{R} \times\left(q L_{\mathrm{amb}}^{2} /[k T \times(1+\gamma+\delta)]\right)}{\mu_{n}^{o} \tau_{n}^{R}-q L_{\mathrm{amb}}^{2} /[k T \times(1+\gamma+\delta)]}
$$

where $\mu_{n}^{o} \tau_{n}^{R}$-products for majority carriers are obtained from the measured $\sigma_{\mathrm{ph}}$.

Several important conditions should be met in the SSPG experiment: (i) the applied voltage should be in the Ohmic region of the $I-V$ curve; (ii) the $\beta$-value should not change with increasing voltage; (iii) the sample should not be heated due to high power illumination by the laser beam; (iv) a higher generation rate should be used in order to decrease errors in the experiment for films with a low-level signal; (v) for the $\mu \mathrm{c}-\mathrm{Si}: \mathrm{H}$ films, there is some deviation from the straight line of the Balberg plot due to surface scattering and surface recombination for small grating periods $(\Lambda<2 \mu \mathrm{m})$ and for low illuminations, one has to take only linear part of the Balberg plot to extract $L_{\text {amb }}$; (vi) $\alpha d$ should be less 
than 1 for uniform absorption, where $\alpha$ is the absorption coefficient and $d$ is the thickness of the films. Care has been taken to meet all these requirements for the SSPG measurements on $\mu \mathrm{c}-\mathrm{Si}: \mathrm{H}$ in the present study.

\section{Results and discussion}

Undoped $\mu \mathrm{c}-\mathrm{Si}: \mathrm{H}$ films prepared with varying silane concentrations exhibit different crystalline volume fractions, which decreases as the SC increases. The normalized Raman spectra of the $\mu \mathrm{c}-\mathrm{Si}: \mathrm{H}$ films studied in this work are shown in Fig. 2. The Raman spectra show the characteristic resonances at $520 \mathrm{~cm}^{-1}$ and $500 \mathrm{~cm}^{-1}$ of the crystalline phase and at $480 \mathrm{~cm}^{-1}$ of the amorphous and disordered phase. It can be seen that the contribution at $480 \mathrm{~cm}^{-1}$ is considerably larger for the $\mathrm{SC}=6.3 \%$ film

The steady-state photoconductivity was measured on these $\mu \mathrm{c}-\mathrm{Si}$ : $\mathrm{H}$ films for a wide range of generation rates. The steady-state photoconductivity is dominated by the majority carrier transport, i.e. electrons for this undoped material which is slightly $n$-type. From the steady-state photoconductivity, the majority carrier $\mu_{n}^{o} \tau_{n}^{R}$-products can be evaluated. The $\mu_{n}^{o} \tau_{n}^{R}$-products are plotted versus generation rate in Fig. 3. The $\mu_{n}^{o} \tau_{n}^{R}$-products decrease as generation rate increases and obey the expected relation; $\mu_{n}^{o} \tau_{n}^{R} \propto \mathrm{G}^{\gamma-1}$. The exponent $\gamma$ is the lowest for $\mathrm{SC}=3.1 \%$ with $\gamma=0.60$. For the other films $\gamma$ is between 0.78 and 0.94 , showing no functional dependence on the SC.

Although steady-state photoconductivity measurements were carried out under the applied voltages up to $100 \mathrm{~V}$ in the Ohmic region of contacts, these voltages may not be suitable for the SSPG measurements. For this reason, the photocurrents ratio $\beta\left(=J_{\text {coh }} / J_{\text {incoh }}\right)$ for different grating periods should be carefully measured for the same applied voltages of Ohmic region in order to make certain that transport is not influenced by the strong electric fields. An example of the $\beta$-values versus electric field is shown in Fig. 4 for an a-Si: $\mathrm{H}$ film and three different $\mu \mathrm{c}-\mathrm{Si}: \mathrm{H}$ films. Even though contacts were Ohmic for the electric fields of up to $2000 \mathrm{~V} \mathrm{~cm}^{-1}$ for steady-state photoconductivity measurement, the $\beta$ -

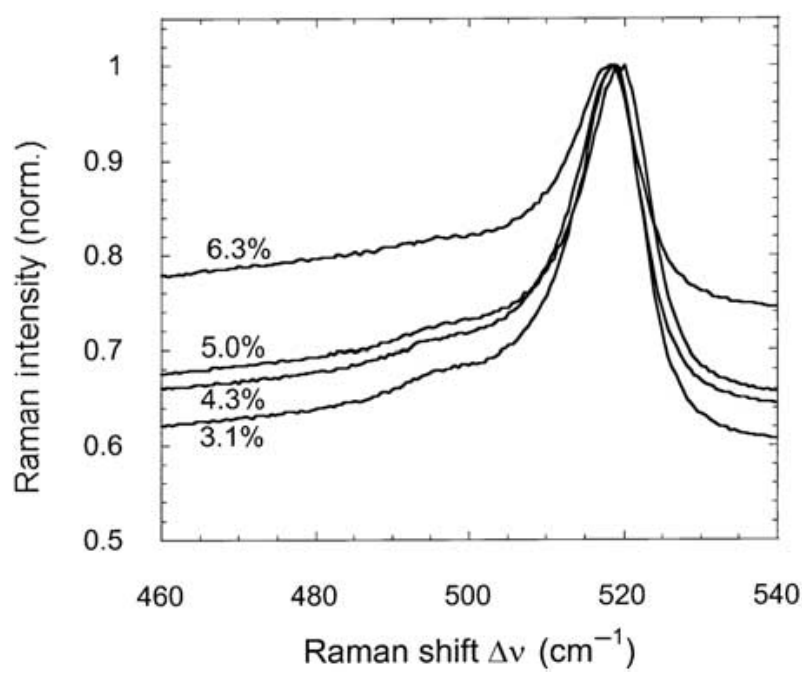

Figure 2 The normalized Raman spectra of the $\mu \mathrm{c}-\mathrm{Si}: \mathrm{H}$ films prepared using VHF-PECVD system for the SCs from $3.1 \%$ to $6.3 \%$.

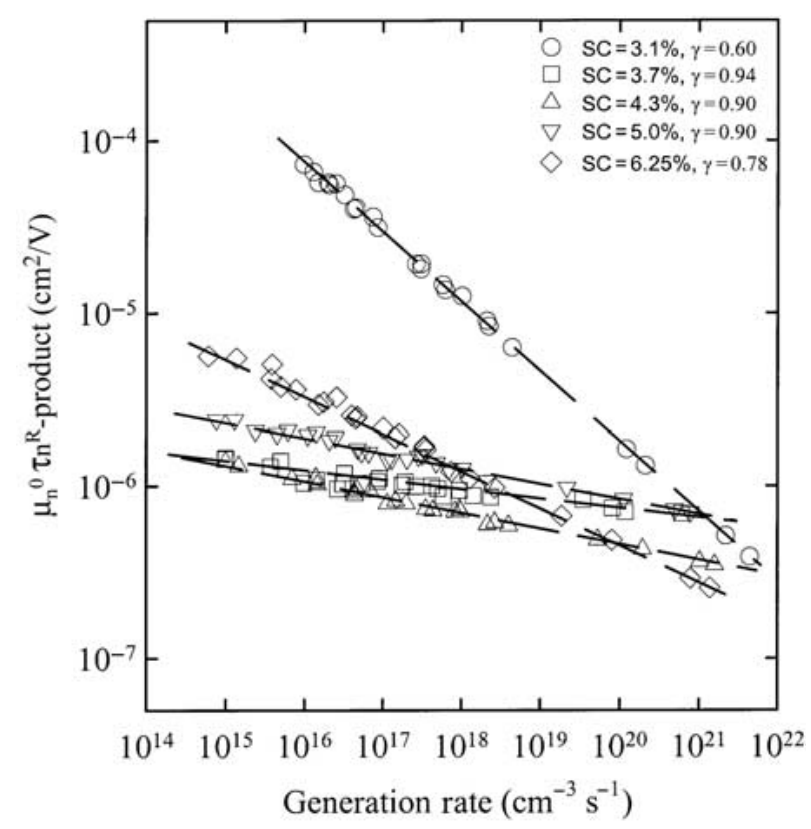

Figure 3 Majority carrier $\mu_{n}^{o} \tau_{n}^{R}$-products versus generation rate for the $\mu \mathrm{c}-\mathrm{Si}$ : H samples.

values are independent of the electric fields only up to $300 \mathrm{~V} \mathrm{~cm}^{-1}$. For the higher electric fields, the $\beta$ becomes field dependent and the transport is not diffusion controlled any more. For each sample, measurements of the $\beta$-values for different grating periods were carried out in the low electric field region, where the $\beta$-values were constant.

Experimental results of the photocurrents ratio, the $\beta=J_{\text {coh }} / J_{\text {incoh }}$, versus the grating period $\Lambda$ are shown in Fig. 5 (symbols) for an a-Si: $\mathrm{H}$ and three different $\mu \mathrm{c}$ $\mathrm{Si}: \mathrm{H}$ films. The $\beta$-values change strongly for pure a$\mathrm{Si}: \mathrm{H}$ film as reported previously [8] and becomes negative for the grating periods higher than $1 \mu \mathrm{m}$. For the $\mu \mathrm{c}-\mathrm{Si}: \mathrm{H}$ films, the $\beta$-values decrease less with grating period. The $\beta$-values reach negative values only for the $\mathrm{SC}=6.3 \%$ sample, which has the highest amorphous volume fraction as seen from the Raman spectra of Fig. 2, above $\Lambda=2.5 \mu \mathrm{m}$. The rate of decrease in the $\beta$ decreases and the $\beta$ curve becomes less dependent on $\Lambda$ for the highest crystalline volume fraction $\mu \mathrm{c}-\mathrm{Si}: \mathrm{H}$ films prepared with the lowest SC's

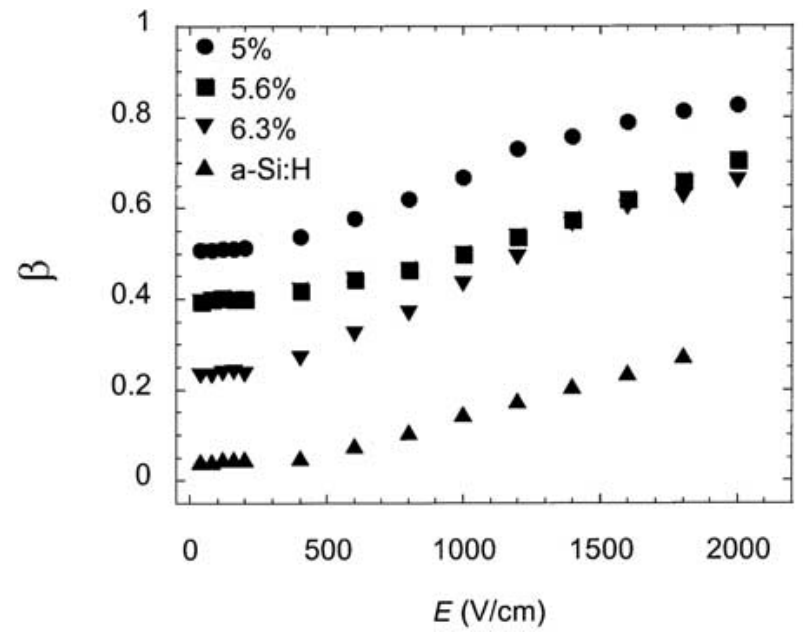

Figure 4 Electric field dependence of experimental $\beta$-values for the grading period of $1 \mu \mathrm{m}$ for an a-Si : $\mathrm{H}$ and three $\mu \mathrm{c}-\mathrm{Si}: \mathrm{H}$ films. 


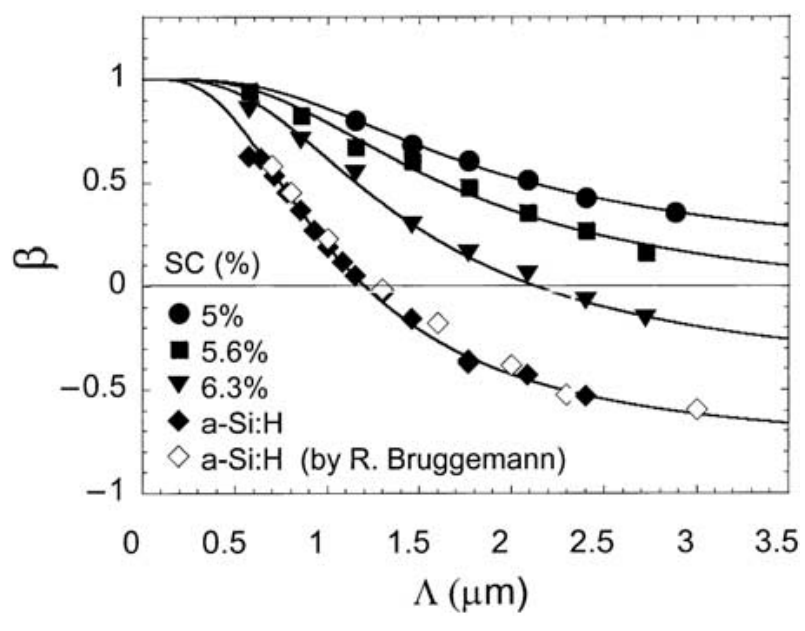

Figure 5 Experimental $\beta$ versus the grating period $\Lambda$ (closed symbols) for undoped a-Si:H and $\mu \mathrm{c}-\mathrm{Si}: \mathrm{H}$ films. Open diamond symbols are measured by R. Bruggemann at University of Oldenburg on the same a$\mathrm{Si}: \mathrm{H}$ film. The solid lines are fits to the data using the Equation 1.

(data not shown). The change in the $\beta$ is not only controlled by the $L_{\mathrm{amb}}$ but also the grating quality parameter $\phi$ as defined in Equation 1 [9]. For this reason, both parameters, $L_{\mathrm{amb}}$ and $\phi$, of the Equation 1 were obtained simultaneously using the theoretical $\Lambda$ data and the best fits to the experimental $\beta$-values. The best fit results of the $\beta$ are shown in the Fig. 5 as solid lines. As theoretically expected, for the lower $\Lambda$ values $\left(\Lambda<L_{\mathrm{amb}}\right)$, the grating disappears and the $\beta$ becomes unity for all the samples. The $L_{\mathrm{amb}}$ obtained for the $\mathrm{SC}=3.1 \%$ is $86 \mathrm{~nm}$. It increases with increasing the SC and peaks at $200 \mathrm{~nm}$ for the $\mathrm{SC}=5.6 \%$ as shown in Fig. 6 . Then, $L_{\mathrm{amb}}$ decreases to lower values, towards that of pure amorphous silicon as the amorphous volume fraction of microstructure increases with increasing the $\mathrm{SC}$. The data for the pure a-Si : H sample was measured in the light soaked state to prevent the light induced degradation effect in measured photocurrents due to high intensity of laser illumination during the measurement. In addition, SSPG measurement on the same a-Si : $\mathrm{H}$ film at the same light soaked condition was also carried out by R. Bruggemann at University of Oldenburg approximately at the same generation rate. A good agreement has been found between two independent measurements carried out on the same a-Si:H as shown as open diamond symbols in Fig. 5. For each sample, the $\beta$ versus the grating period were measured for generation rates between $10^{19}$ and $10^{21} \mathrm{~cm}^{-3} \mathrm{~s}^{-1}$ in order to see the dependence of the $L_{\mathrm{amb}}$ on the generation rate. The $L_{\mathrm{amb}}^{2}$ versus generation rate change very slowly (data not shown) for all the samples, except the $\mathrm{SC}=3.1 \%$. The

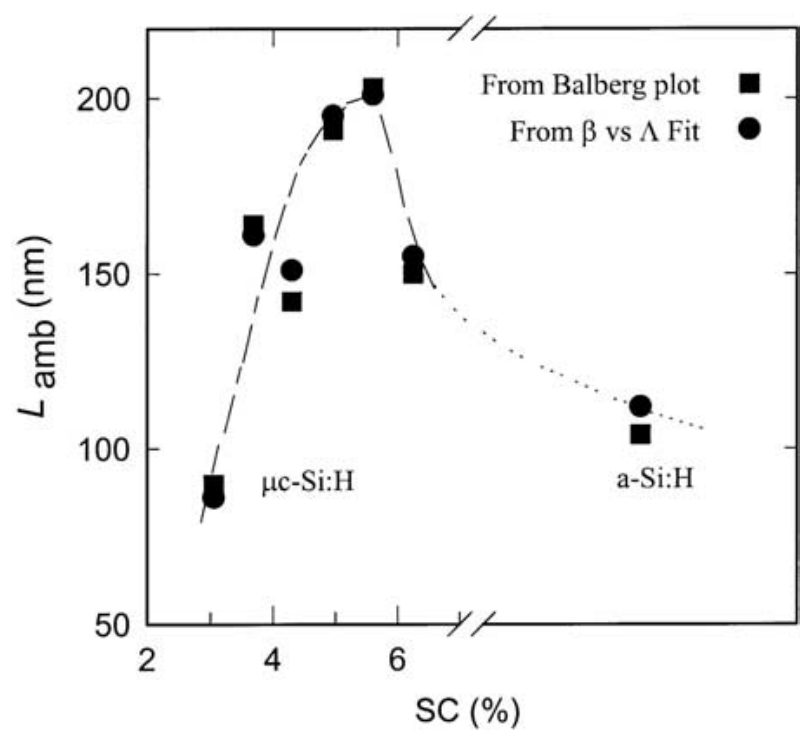

Figure $6 L_{\text {amb }}$ versus silane concentration obtained from the best fits to data of Fig. 5 (circles) and those from the intercept of the Balberg's plots (squares). The dashed lines are guide to eye.

exponent $\delta$ in the relation, $L_{\text {amb }}^{2} \propto G^{\delta}$, is found to be very small as given in Table I. The grating quality factor $\gamma_{0}$ was calculated for the samples as described above. As summarized in Table I, the grating quality factor $\gamma_{0}$ values are high, changing from 0.70 to 1.0. These indicate that films show high grating quality and no significant surface roughness affecting the SSPG measurements [9].

Furthermore, the $L_{\mathrm{amb}}$ values were also obtained from the intercept of the Balberg's plot as commonly practiced $[3,8]$. An example of the Balberg plots were also shown in Fig. 7 for an a-Si : $\mathrm{H}$ and two $\mu \mathrm{c}-\mathrm{Si}: \mathrm{H}$ films. A straight line can generally be obtained from the best fit to the $\Lambda^{-2}$ versus $[2 /(1-\beta)]^{1 / 2}$ for $\Lambda$ values higher than $1 \mu \mathrm{m}$. The $L_{\mathrm{amb}}$ values calculated from the intercept of the Balberg plot are shown in Fig. 6 as a function of the SC. The $L_{\text {amb }}$ values found from the Balberg's approach also show the similar functional dependence on the $\mathrm{SC}$, where $L_{\mathrm{amb}}$ peaks around the $\mathrm{SC}=5 \%$. However, a small difference of around $5 \%$ exists in the calculated $L_{\mathrm{amb}}$ values from the intercept of the Balberg plot for most of the samples. Such a small error is generally introduced by the measurement error in larger $\beta$-values as previously reported [9].

The $L_{\mathrm{amb}}$ values obtained from the best fits to data of Fig. 5 and the majority carrier (electrons) $\mu_{n}^{o} \tau_{n}^{R}$-products obtained from the $\sigma_{\mathrm{ph}}$ are used to calculate the minority carrier (hole) $\mu_{p}^{o} \tau_{p}^{R}$-products using the Equation 4 . Those values calculated for the highest generation rates are

T A B L E I A summary of steady-state photoconductivity and SSPG results for a-Si:H and $\mu \mathrm{c}-\mathrm{Si}: \mathrm{H}$ films

\begin{tabular}{|c|c|c|c|c|c|c|c|c|c|c|c|c|}
\hline $\mathrm{SC}(\%)$ & $d(\mu \mathrm{m})$ & $\begin{array}{l}G \times 10^{21} \\
\left(\mathrm{~cm}^{-3} \mathrm{~s}^{-1}\right)\end{array}$ & $\gamma$ & $\begin{array}{l}L_{\mathrm{amb}} \\
(\mathrm{nm})\end{array}$ & $\begin{array}{l}L_{\text {Balberg }} \\
(\mathrm{nm})\end{array}$ & $\phi$ & $\begin{array}{l}\mu_{n}^{o} \tau_{n}^{R} \times 10^{-7} \\
\left(\mathrm{~cm}^{2} \mathrm{~V}^{-1}\right)\end{array}$ & $\begin{array}{l}\mu_{p}^{o} \tau_{p}^{R} \times 10^{-9} \\
\left(\mathrm{~cm}^{2} \mathrm{~V}^{-1}\right)\end{array}$ & $\gamma_{0}$ & $\gamma_{d}$ & $b$ & $\delta$ \\
\hline 3.1 & 0.4 & 2.2 & 0.60 & 86 & 90 & 0.35 & 5.20 & 2.0 & 0.79 & 0.93 & 354 & 0.48 \\
\hline 3.7 & 0.62 & 0.6 & 0.94 & 161 & 164 & 0.7 & 6.90 & 4.9 & 0.88 & 0.99 & 129 & 0.02 \\
\hline 4.3 & 0.6 & 1.6 & 0.90 & 151 & 142 & 0.60 & 3.47 & 5.0 & 0.94 & 0.96 & 78 & -0.06 \\
\hline 5 & 0.7 & 0.8 & 0.91 & 195 & 191 & 0.45 & 7.01 & 8.0 & 0.71 & 1.00 & 86 & -0.01 \\
\hline 5.6 & 0.73 & 1.6 & 0.91 & 201 & 203 & 0.53 & 1.94 & 7.0 & 0.76 & 1.00 & 26 & -0.04 \\
\hline 6.3 & 0.78 & 1.4 & 0.78 & 155 & 150 & 0.72 & 2.55 & 5.6 & 0.97 & 0.99 & 44 & -0.04 \\
\hline a-Si:H & 1.0 & 0.6 & 0.87 & 112 & 104 & 0.94 & 0.38 & 2.2 & 1.00 & 0.94 & 16 & -0.12 \\
\hline
\end{tabular}




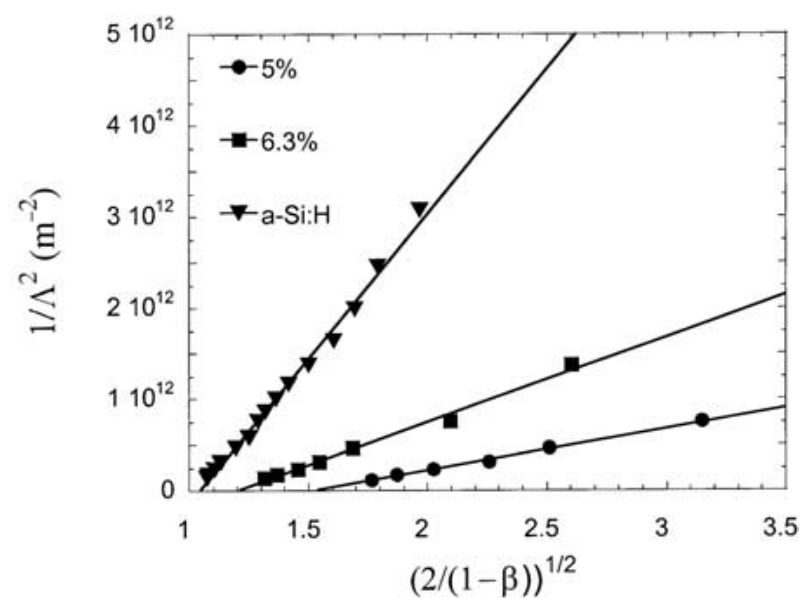

Figure 7 The Balberg plots of an a-Si:H and two $\mu \mathrm{c}-\mathrm{Si}: \mathrm{H}$ films obtained from the experimental $\beta$ and $\Lambda$ (symbols). The solid lines are the best fits to data using the Equation 2.

shown in Table I. The $\mu_{p}^{o} \tau_{p}^{R}$-products are in the range of $2-8 \times 10^{-9} \mathrm{~cm}^{2} \mathrm{~V}^{-1}$, which are much lower than the majority carrier $\mu_{n}^{o} \tau_{n}^{R}$-products changing from 0.6$1.2 \times 10^{-6} \mathrm{~cm}^{2} \mathrm{~V}^{-1}$ as seen in Fig. 3. However, both majority and minority carrier $\mu \tau$-products for the $\mu \mathrm{c}$ $\mathrm{Si}$ : $\mathrm{H}$ films are still higher than those of pure amorphous silicon film for the similar generation rates as indicated in Table I. This is consistent with the recent results reported, where higher $\mu \tau$-products were also predicted from the solar cells characteristics having different $\mu \mathrm{c}-\mathrm{Si}: \mathrm{H}$ absorber layers [11,12]. Derived $L_{\mathrm{amb}}$ values and measured $\sigma_{\mathrm{ph}}$ data were also used to find the Fermi level parameter $b$. The parameter $b$ calculated using the Equation 3 are shown in Table I. It is 16 for a-Si: $\mathrm{H}$ and changes from 26 to 354 for the $\mu \mathrm{c}-\mathrm{Si}: \mathrm{H}$ films, indicating that the $\mu \mathrm{c}-\mathrm{Si}: \mathrm{H}$ films show slightly $n$-type behaviour. These values of minority carrier $\mu_{p}^{o} \tau_{p}^{R}$-products, $L_{\mathrm{amb}}$, and $\sigma_{\mathrm{ph}}$ found in this work are in the same range with those reported previously for the hydrogenated microcrystalline silicon films $[1,4]$.

\section{Conclusions}

We have carried out steady-state photoconductivity and steady-state photocarrier grating measurements on undoped $\mu \mathrm{c}-\mathrm{Si}: \mathrm{H}$ films prepared in a VHF-PECVD system with different silane concentrations. We have fully applied all the required conditions of SSPG method to obtain reliably the ambipolar diffusion lengths, $L_{\mathrm{amb}}$, and the grating quality parameter $\phi$ in $\mu \mathrm{c}-\mathrm{Si}: \mathrm{H}$ samples. $L_{\mathrm{amb}}$ increases with the SC and peaks at $200 \mathrm{~nm}$ for the $\mathrm{SC}=5.6 \%$, then decreases again for higher SCs. The highest $L_{\text {amb }}$ is obtained for the $\mu \mathrm{c}-\mathrm{Si}: \mathrm{H}$ films prepared with the SC around 5\%, which is close to the amorphous phase transition and results in highest efficiency solar cell as reported before [10]. Those values obtained from the Balberg plot show the similar dependence on the SC. However, a small difference of around 5\% exists in calculated $L_{\mathrm{amb}}$ values from the intercept of the Balberg plot. The films show high grating quality factor $\gamma_{0}$, indicating very small surface roughness affecting the SSPG measurements. The minority carrier (hole) $\mu_{p}^{o} \tau_{p}^{R}$ products derived from the measured $L_{\mathrm{amb}}$ and the steadystate photoconductivity are much lower than those of majority carrier electrons. However, both majority and minority carrier $\mu \tau$-products for the $\mu \mathrm{c}-\mathrm{Si}: \mathrm{H}$ films are still higher than those of pure amorphous silicon film, which is also consistent with the results obtained from the $\mu \mathrm{c}-\mathrm{Si}: \mathrm{H}$ solar cell characteristics $[11,12]$. and the Fermi level parameter $b$ varies from 26 to 354 . The results reported here are consistent with the corresponding data reported in the literature $[1,4]$ for hydrogenated microcrystalline silicon films.

\section{Acknowledgments}

Authors thank to $\mathrm{Dr}$ R. Bruggemann for SSPG measurement on undoped a-Si:H film and D. Akdaş for helping measurements. This joint project is partially supported by the International Bureau of the BMBF, Germany and The Scientific and Technical Research Council of Turkey (TÜBITTAK) under the project number TBAG-U/14.

\section{References}

1. C. DROZ, M. GOERLITZER, N. WYRSCH and A. SHAH, J. Non-Crystall. Solids 266 (2000) 319.

2. O. VETtERL, A. GROSS, T. JANA, S. RAY, A. LAMBERTZ, R. CARIUS and F. FINGER, ibid. 299 (2002) 772.

3. M. GOeRlitzer, P. TORRES, C. DroZ and A. SHAH, Solar Energy Mater. Solar Cells 60 (2000) 195.

4. M. GOERlitZer, N. BECK, P. TORRES, J. MEIER, N. WYRSCH and A. SHAH, J. Appl. Phys. 80 (1996) 5111.

5. D. R. RITTER, E. ZELODOV and K. WEIZER, ibid. 62 (1987) 4563.

6. C. D. A BEL and G. H. B AUER, Prog. Photovoltaics: Res. Appl. 1 (1993) 269.

7. C. M. FORTMANN, J. O'DOWD, N. NEWTON and J. FISHER, in AIP Conference Proceedings, vol. 157 (1987) p. 103.

8. I. B AlbeRG, K. A. EPSTEIN and D. RitTer, Appl. Phys. Lett. 54 (1989) 2461.

9. R. BR ÜGGEMANN, ibid. 73 (1998) 499.

10. O. Vetterl, F. Finger, R. CARiUs, P. HAPKe, L. HOUBEN, O. KLUTh, A. LAMBERTZ, A. MUCK, B. RECH and H. WA GNER, Solar Energy Mater. Solar Cells 62 (2000) 97.

11. A. GRoss, O. VetTERL, A. LAMBERTZ, F. Finger, H WAgner and A. DASGUPtA, Appl. Phys. Lett. 79 (2001) 2841.

12. O. VETtERL, A. LAMBERTZ, A. DASGUPTA, F. Finger, B. RECH, O. KLUTH and H. WA GNER, Solar Energy Mater. Solar Cells 66 (2001) 345.

Received 2 June

Revised 5 July 2003 